Introduction An important group of working women has been laid aside of research: housewives and micro entrepreneurs. Perhaps multiple roles are detrimental to housewives' both physical and mental health; it is supposed that these damaging effects are worst in the case of women taking care of housekeeping tasks and being workers at the same time. Therefore: how housewives, female microentrepreneurs, workers and professionals compare in the above mentioned fields?

Methods 353 women were surveyed in Cuernavaca, Mexico. $25 \%$ were housewives, $21 \%$ were housewives which sold goods or rendered services (baby sitting, laundry, ironing, for instance) to people outside the family circle, $13 \%$ were housewives and micro entrepreneurs at the same time, 5\% said were blue-collar workers and housewives, 7\% saw themselves as clerks and house-wives, $21 \%$ were professionals and housewives, and 5\% saw themselves as professionals without being housewives at the same time.

The BREF-WHOQOL, the Siegrist Effort-Reward Questionnaire (slightly modified to adapt it to the sample), a stress, and self-efficacy, self-esteem, sense of life as well as a demographic questionnaire were administered.

Results MANOVAS were calculated for the whole sample. Housewives rendered the lowest scores in mental health and self-efficacy, followed by micro-entrepreneurs, and manual workers. Regarding mental health, office employees, professionals and women without being housewives were better off as well as considering self-esteem, physical health, stress and recognition from their families. Stress correlated egatively with family satisfaction, recognition from their family, physical health, self-efficacy, self-esteem, and mental health. Effort was positively associated with stress, and negatively with the rest of variables. However, from a practical viewpoint scores were minor, mounting to less than a point.

Conclusion Protective factors balance negative ones. Public policies should aim to pay attention to housewives since their important role within families impact in children and husbands as well as to society.

\section{Work and Vision}

\section{WORK AND VISION}

${ }^{1}$ Miguel S Kabilio*, ${ }^{2}$ Agueda Muñoz del Carpio Toia. ${ }^{1}$ Australia and New Zealand Society of Occupational Medicine (ANZSOM), Perth, Australia; ${ }^{2}$ Universidad Catolica de Santa Maria, Arequipa, Peru

\subsection{6/oemed-2018-ICOHabstracts. 1525}

Aim of special session Investigate, diagnose work-related and environment-related ocular conditions

Apply appropriate ergonomic work conditions for reducing occupational asthenopia.

Promote healthy work lighting

${ }^{1}$ Prof Bruno Pisaniello, ${ }^{2}$ Dr Peder Wolkoff, ${ }^{3}$ Prof Bruno Piccoli

${ }^{1}$ School of Public Health, University of Adelaide, South Australia, Australia

${ }^{2}$ National research Centre for the Working Environment, Copenhagen, Denmark

${ }^{3}$ Institute of Public Health - Section of Occupational Health, Catholic University of the Sacred Heart, Roma, Italy

\section{8a OFFICE LIGHTING SURVEYS - REFOCUSSING ON THE} EYE AND HEALTH

${ }^{1}$ Dino Pisaniello*, 'Sharyn Gaskin, ${ }^{2}$ Marco D'Orso, ${ }^{3}$ Bruno Piccoli. 'School of Public Health, University of Adelaide, Adelaide, Australia; ${ }^{2}$ School of Medicine, University of Milan Bicocca, Monza, Italy; ${ }^{3}$ Institute of Public Health - Section of Occupational Health, Catholic University of the Sacred Heart, Rome, Italy

\subsection{6/oemed-2018-ICOHabstracts. 1526}

Introduction Current guidance on office lighting tends to be oriented towards illumination engineering, i.e. achieving a certain lighting environment. The selection of lamps and luminaires from a vast array of current lighting options, as well as their layout, often reflects architectural style and energy efficiency, rather than 'healthy' lighting - which aims to eliminate or minimise adverse health effects, including visual discomfort, arising from visual tasks and ambient light sources.

Methods Firstly, this paper explores the criteria for healthy lighting based on visual anatomy and pathophysiology and characteristics of workers and tasks in office environments. Secondly, survey methods addressing characteristics of light entering the eye are reviewed in the context of outcomes ranging from discomfort to retinal degradation.

Results A primary consideration is characterisation of light sources in the occupational visual field, (OVF) which is mainly determined by the visual tasks. Another consideration is how, and for how long, the source(s) are imaged on the retina (especially the macula). Again this depends on the visual requirements of the task. Indeed, directionality is much more important for lighting than other hazards such as noise. Such assessments are not possible with an integrating light measuring instrument such as a lux metre. Finally, in the cases of blue-rich sources, the assessment should be more about radiometry than photometry.

Discussion A variety of visual, circadian rhythm and psychological disturbances may arise from inappropriate lighting. The concept of 'healthy' lighting serves to integrate the issues, and surveys of lighting should begin with the OVF and systematic consideration of light sources therein. Assessment should involve luminance and where necessary radiance.

\section{8b PREVALENCE AND RISK FACTORS OF EXTERNAL EYE SYMPTOMS INDOORS}

Peder Wolkoff. National Research Centre for the Working Environment, Lersø Parkallé 105, 2100 Copenhagen, Denmark

\subsection{6/oemed-2018-ICOHabstracts. 1527}

Introduction Eye irritation is generally among top-3 reported symptoms in office environments. The symptoms are especially among middle and advanced ages and particularly among women more than men. The eye symptoms are the most commonly reported complaints in the eye clinic. A multidisciplinary understanding of potential risk factors is necessary to interpret the high prevalence of eye symptoms.

Methods Literature from 2012 to June 2017 has been updated in context of dry eye (DE) symptom reporting in office-like environments by searches in the public databases and previous reviews. 